\title{
EL ARTISTA FANTASMA Y LA MÁQUINA MITOLÓGICA
}

Raúl Antelo*

Universidade Federal de Santa Catarina

...there was one, the ghost artist, and there was one

about the famous so-called Inje-Inje, which John

Baur at the Whitney Museum wrote about...

Holger Cahill, en entrevista para los

Archives of American Art, Smithsonian Institution, abr. 1960

Todos recordamos la asociación que hace Benjamin entre la ficción de Kafka y el mundo primordial de las hetairas. Las fuentes para esas consideraciones benjaminianas respecto de la proto-historia remontan a los estudios de uno de los participantes en el congreso de filosofía de Mendoza, Ludwig Klages (Von Kosmogonischen Eros, 1922), y además a los escritos de Johann Jakob Bachofen (1815-1887), autor sobre el cual Benjamin llegó a escribir un pequeño estudio, en francés, en 1934, donde lo parangona a Aby Warburg, como ejemplo del teórico grand seigneur, a la manera de Aloïs Riegl, por su rescate de lo bizarro, y a su complemento, el anarquista Elisée Reclus, por su teoría omnicomprensiva de espacios y tiempo. ${ }^{1}$ Pero hay otro aspecto de la teoría de Bachofen que me gustaría

\footnotetext{
* Raúl Antelo es profesor en la Universidade Federal de Santa Catarina y lo ha sido en las de Yale, Duke, Texas at Austin, Autónoma de Barcelona y Leiden. Ha publicado Literatura em Revista; Na ilha de Marapatá; Parque de diversões Aníbal Machado; Algaravia. Discursos de nação; Transgressão \& Modernidade; Potências da imagem; María con Marcel. Duchamp en los trópicos y Crítica acéfala. Editó, entre otros títulos, la Obra Completa de Oliverio Girondo y Antonio Candido y los estudios latinoamericanos. Ha colaborado en la Historia social de la literatura argentina de D. Viñas, en la Historia de la literatura argentina de Noé Jitrik y en varios libros colectivos, el más reciente, Nove abraços no inapreensível. Filosofia e arte em Giorgio Agamben (2009). "Tiempos de Babel. Destrucción y anacronismo" se lee en la revista Quimera, Barcelona, julio de 2008, y "Postautonomía: pasajes" acaba de salir en Pasajes de Pensamiento contemporáneo, Valencia, 2008-9.

1 Cf. Benjamin, Walter, "Johann Jakob Bachofen" in Selected writings. Ed. Michael Jennings. Belknap/Harvard, 2002, 11-24. Sobre Reclus me detuve en "As Flores do Mal: sintoma e saber antimodernos" in Alea.Vol. 9, № 1, Rio de Janeiro, 2007, 152-164.
} 
recordar aquí. En su ensayo sobre el teórico de Basilea, recientemente editado de forma póstuma, Furio Jesi (1941-1980) ilumina un aspecto de la teoría de la máquina mitológica, tributaria de las tesis sobre filosofía de la historia de su antecesor, que vale la pena recordar en este punto extremo del Atlántico Sur:

\begin{abstract}
Mentre il rapporto con l'antico, fin dalle prime riscoperte dei monumenti romani e greci, ha dato vita nella cultura occidentale ad un filone di indagini esoteristiche, parallele e sovente intrecciate a quelle propriamente filologiche, il rapporto con $i$ "selvaggi", fin dagli esordi dell'etnografia e dell'etnologia, è di solito rimasto alieno da un approccio di tal genere: quasi che $i$ diversi in quanto antichi possedessero segreti $e i$ diversi in quanto "selvaggi" ne fosero privi. Ricorderemo un solo esempio. Il benedettino Dom Pernety, archeologo, filologo, esoterista, da un lato era disposto a riconoscere nella tradizione mitologica circa la guerrra di Troia i simboli dell'operazione alchemica, d'altro lato, nella relazione del suo viaggio con Bougainville alle Isole Malvine, si limitava ad assumere la parte dell'etnografo e descriveva $i$ costumi dei "selvaggi" senza ricercarvi alcun segreto, da puro e semplice viaggiatore curioso e discretamente obiettivo. (Jesi, 2005:25) ${ }^{2}$
\end{abstract}

Jesi nos dice, en pocas palabras, que, para ecuacionar las relaciones entre lo antiguo y lo salvaje, es necesario, antes que nada, analizar los modelos gnoseológicos utilizados para producir las múltiples categorías de lo diverso a la que recurrimos de manera poco meditada. Nos dice que esos primeros viajeros a

${ }^{2}$ Cf. Jesi, Furio. Bachofen. Torino: Bollati Boringhieri, 2005, 25. Anteriormente, en Mito (1973), decía Jesi: "Neste quadro global, Creuzer e Bachofen colocam-se imediatamente a uma luz equívoca aos olhos daqueles que do lluminismo tinham escolhido unicamente a 'face luminosa', arrastando a luz para a 'objectividade filológica'. Tanto Creuzer como Bachofen dirigiam-se, pelo contrário, às 'profundidades do ser e do pensamento', à região obscura que se apresentava como um perigo, como um terreno de perigosas areias movediças ou de pântanos cheios de fantasmas, frente às certezas iluministas. E o perigo era particularmente grande porque a essência do pensamento iluminista implicava uma precisa dialéctica entre luz e trevas, que desaguava frequentemente em exorcismo das trevas: na luz entendida como 'o contrário das trevas', mais do que na convicção agostiniana- da 'treva' como 'ausência de luz'. Creuzer era culpado de ter atribuído à 'ciência' do símbolo e do mito -por conseguinte, à filologia- características de 'ciência' do sentido da história. Mais culpado ainda era Bachofen, o qual propunha um fundamento funerário da propriedade (núcleo da propriedade é a propriedade fundiária, núcleo da propriedade fundária é o túmulo) e punha o estudioso da mitologia frente à responsabilidade rousseauiana de exegeta das características das sociedades 'primitivas' e, por conseguinte, de todas as sociedades humanas, graças à equivalência 'primitivo' = 'primordial', portanto fundamento perene" Cf. Idem - O Mito. Trad. Lemos de Azevedo. Lisboa, Presença, 1977, 70. 
Malvinas eran esotéricos en la medida en que reconocían, en las formas simbólicas, la precedencia de antiguos esquemas, pero, no obstante, eran igualmente científicos en cuanto, aboliendo el secreto, describían usos y prácticas culturales con una supuesta objetividad universal. Jesi planta así, en el corazón mismo del mito (la fábula), el espejo de la mitología (la ficción). Nos dice pues que la lógica de la representación (la historia) es minada entonces por el régimen de la verdad (la ambivalencia). Y explica:

\begin{abstract}
Nell'attribuire ai diversi-antichi e non ai diversi-selvaggi la proprietà del segreto, gli esoteristi non si limitano a custodire passivamente la loro ricchezza, ma la difendono attivamente, ussufruendo della dimensione temporale (in cui collocano l'esibizione dei beni) per conferire fondamento alla progettazione della durata dei beni esibiti. La sfera dei diversi-antichi custodisce come un astuccio definitivamente suggellato la radice del segreto, inteso quale differenza per eccellenza. Nel dicchiarare riposta laggiù quella radice, gli esoteristi la pongono deliberatamente al riparo dai turbamenti della storia: al sicuro, in un luogo ove essa non potrà mai essere tagliata e quindi potrà sempre fondare e alimentare la durata futura della pianta. I diversi-selvaggi, che godono della contemporaneità con gli esoteristi, sono invece esposti quotidianamente ai pericoli della storia -e tanto più dall'istante in cui la loro scoperta da parte dei "civili" ha rotto le ultime barriere che separavano il loro tempo da quello dei "civili", la loro storia dalla storia d'Europa-. Ciò significa, d'altronde, che la vera diversità, la diversità per eccellenza, quella che può coincidere con il segreto in quanto somma diversità, è solo la diversità nel tempo, poiché solo la diversità nel tempo è configurabile come efficace elemento di rottura del modello della storia quale unico continuum. E proprio tale rottura è l'obiettivo preliminare delle dottrine e delle prassi esoteriche. (27-28)
\end{abstract}

En 1916 un poeta claramente esotérico, Ezra Pound, pretendía traducir un texto de Vicente Huidobro, Horizon carré, al inglés. Ese mismo año, en su "Arte Poética", el poeta chileno se preguntaba, "Por qué cantáis la rosa, joh Poetas!/ Hacedla florecer en el poema", idea que poco después el mismo Huidobro admitiría, en francés, que le había sido trasmitida, como en una revelación, a él mismo, por un poeta aimará: "esta idea del artista como creador absoluto, del Artista-Dios, me la trasmitió un viejo poeta indígena de Sudamérica (aimará) que dijo: 'El poeta es un dios; no cantes a la lluvia, poeta, haz llover'”. ${ }^{3}$ Asimismo, el mexicano José Juan

\footnotetext{
3 "Cette idée de l'artiste créateur absolu, de l'Artiste-Dieu me fut suggérée par un vieux poète indien de l'Amérique du Sud (Aïmara) qui dit: 'Le poète est un Dieu, ne chante pas la pluie, poète, fais pleuvoir". A lo que Huidobro agrega su ponderación decimonónica y autonomista: "Bien que l'auteur de ces vers tombât dans l'erreur de confondre le poète avec le magicien et de croire que l'artiste pour se montrer créateur doit troubler les lois du monde, alors que ce qu'il doit faire c'est créer son monde
} 
Tablada también registró, en 1923, que la caída de los viejos patrones del arte grecorromano inclinaba a los artistas modernos hacia lo primitivo en Etruria, Asia, África y América, en una búsqueda ardiente del Paraíso Perdido y sus frutos dorados, a través de la visión directa, la forma pura y la expresión neta. El 8 de abril de ese año, tras dictar una conferencia sobre arte mexicano en Washington, Tablada copia en su diario un pasaje de la Historia del arte de Élie Faure en que el crítico francés argumenta que una civilización es un fenómeno lírico y es a través de los monumentos que eleva y deja tras de sí que apreciamos su grandeza y calidad. ${ }^{4}$

En esa misma línea de trabajo poético, tenemos, en la Nueva York de 1920, una insólita derivación que no es de fuente científica sino esotérica. En efecto, Holger Cahill (1887-1960) lanza allí el movimiento inje-inje, de declarada inspiración indígena sudamericana. ¿Pero quién era Cahill, figura hoy completamente deslucida? ${ }^{5}$ Recordemos que Holger Cahill organizó las primeras exposiciones sobre arte etnográfico estadounidense, American Primitives y American Folk Sculpture, en el Museo de Newark, entre 1929 y 1931, y más tarde, en 1932, otra, American folk Art: The Art of the Common Man in America, 1750-1900, seguida por American Sources of Modern Art, al año siguiente, en el mismo Museo de Arte Moderno de Nueva York, institución de la que fue director, asistiendo, por lo demás, en esas tareas a Alfred H. Barr Jr. Estudiante de periodismo en la Universidad de

propre et indépendant parallèlement à la nature". Cf. Huidobro, Vicente. "La création pure". L'Esprit Nouveau, № 7, Paris, 1921, 772. L'Esprit Nouveau era la revista del cubismo constructivista animada por Le Corbusier. Su crítico literario era Paul Dermée que defendía una teoría de la modernidad de inspiración baudelairiana. Tanto los ensayos de Dermée como los de Huidobro son de capital importancia en la elaboración del modernismo primitivista de Mário de Andrade. José María Arguedas es otro escritor que podríamos asociar a esta dinámica transcultural. Recordemos sus ensayos sobre "El valor poético y documental de los himnos religiosos kechuas" (La Prensa, Buenos Aires, 28 ene. 1945) o sobre las "Canciones quechuas" (Américas, Washington, Unión Panamericana, № IX, oct.1957, 33-34).

${ }^{4}$ Cf. Tablada, José Juan: Diario (1900-1944). Ed. Guillermo Sheridan. México, Universidad Nacional Autónoma de México, 1992, 221.

${ }^{5}$ Para las informaciones sobre Cahill me baso en el trabajo de Alan Moore, que defendió una tesis sobre el autor en 1996 y a quien agradezco las informaciones recibidas. Debo la primera lectura de ese texto a Antonio Saborit, quien asimismo se ocupó de su traducción al español. Cf Moore, Alan W: "Holger Cahill y el inje-inje. La historia del primitivismo modernista," in Historias. Revista del Instituto Nacional de Antropología e Historia, México, № 61, mayo-ago. 2005. 
Nueva York, Cahill trabó amistad allí con Irwin Granich, más conocido como Michael Gold, el eminente escritor comunista americano. En 1914, Gold le consiguió al amigo su primer trabajo profesional, como editor de dos periódicos de Westchester, el Scarsdale Inquirer y la Bronxville Review. Una crónica de la época los presenta a estos dos recién llegados a los círculos artísticos de Nueva York y los describe, a Gold, como el "moreno judío estadounidense voluble" y, a Cahill, como a "un rubio de ojos azules, fuerte, con la pálida expresión fanática de William Blake", ambos, sin embargo, unidos fervorosamente en torno al movimiento poético inje-inje. ${ }^{6}$

En 1918, efectivamente, Cahill recuerda haber leído una obra etnográfica escrita por un miembro de la Real Sociedad Geográfica, que bien podría ser Exploração na Guiana Brasileira de Alexander Hamilton Rice, donde se narraba la historia de "una tribu en una región localizada entre el Amazonas y los Andes que era tan primitiva que sólo contaba con dos palabras, y el resto de su comunicación lo suplían los gestos. Las palabras eran inje-inje. ${ }^{7}$ Esa esotérica fundación mitológica de Nueva York les hizo prestar atención a otros fenómenos coincidentes. Unos amigos de Cahill, los artistas plásticos John y Dolly Sloan -que, en 1919, habían visitado Santa Fe, en el Nuevo México, inspirados por una figura que por entonces gravitaba en los círculos de vanguardia, el francés Robert Henri, quien a su vez había estado allí previamente, en 1917, llevado por el etnólogo Edgar L. Hewettson los que de algún modo "importan" el arte pueblo a Nueva York. El paisaje del desierto y los ceremoniales de los indios pueblo lo llevaron a Sloan a pintar y a promover, más tarde, en Manhattan, el arte amerindio, exhibiendo, en la muestra de la Sociedad de Artistas Independientes, pinturas de artistas pueblo provenientes de las colecciones del doctor Hewett y de Mabel Dodge Sterne.

Pero a diferencia de Sloan, un esteta, la relación de Cahill con los indígenas americanos tuvo, según un estudioso, Allan W. Moore, una dimensión extra-estética e incluso autobiográfica, que remontaba a su niñez en Dakota del Norte, donde Cahill había conocido a los siux y a los chipecua. Sea como fuere, por experiencia directa o constitución teórica a posteriori, el hecho es que la exposición neoyorkina

\footnotetext{
${ }^{6}$ Cf. Gold, Michael: "Two Critics in a Bar-room”, Liberator, set. 1921, 28-31.

${ }^{7}$ Cf. Cahill, Holger: Entrevista concedida al programa de Historia Oral de Columbia University, Nueva York, 1957, 118.
} 
de los pueblo precipita, de algún modo, la división en el seno mismo de la la Sociedad de Artistas Independientes.

Organizada sobre la base del modelo francés, la Sociedad de Artistas Independientes era fiel reflejo de las ideas estéticas de Robert Henri y, entre sus directores, figuraban tanto realistas antiacadémicos como modernistas radicales. Sin embargo, la contratación de Cahill, como promotor de la exposición de la Sociedad de Artistas Independientes, en febrero de 1921, acabó por desplazar al ex-director de la institución, Hamilton Easter Field y, en poco tiempo, sus actividades al frente de la agremiación precipitaron la división irreconciliable entre sus miembros. E sector más conservador, con Walter Pach a la cabeza, se abatió, con intolerancia iconoclasta, contra las iniciativas de Cahill, tal como quedó reflejado en la exposición de las acuarelas de los indios pueblo. Cahill escribió entonces un artículo sobre esas obras para International Studio, "America Has Its 'Primitives", 8 donde decía apreciar

${ }^{8}$ Cf. Cahill, E. H.: "America Has Its 'Primitives': Aboriginal watercolorists of New Mexico make a faithful record of their race", International Studio, vol. 75, № 299, mar. 1922, 80-83. Al escribir sobre los indios pueblo, Cahill tuvo el antecedente de varios artículos de Hewett, en que se reconocían los rastros previos de Waldo Frank, tal como la nota lingüística sobre la belleza y la felicidad que el mismo Cahill atribuye a Frank. La idea es profícua. Nos permite, al mismo tiempo, pensar la relación entre mito y máquina. Cuando Waldo Frank visitó Amigos del Arte, en Buenos Aires (1929) sus dos primeras conferencias se llamaron "Whitman: El artista, el profeta, el americano" y "Profetas en el arte moderno de Norteamérica. Isadora Duncan y la danza. Alfredo Stiegletz y la pintura. Eugenio O'Neil y el teatro. El desarrollo del jazz. Chaplin y la revolución". Podemos imaginar sus dichos a partir de lo que consigna su libro Ustedes y nosotros, en que Waldo Frank atribuye el papel de padre fundador del clan americano a Alfred Stieglitz: "Stieglitz ha sido fotógrafo. Sus obras están en algunos de los más grandes museos del mundo: Nueva York, Londres, París -en tiempos pasados también en Berlín y Viena-, hasta que el hecho de ser judío quitó todo valor a la obra de este fervoroso americano. Siempre rechazó el término 'artista'; nunca retoca un negativo; y es el enemigo jurado del 'arte fotográfico'. 'Soy un artesano -dice- un hombre que usa una máquina, humildemente, ante la naturaleza'. Muchos de nosotros creemos que sus fotografías de Nueva York, sus estudios de nubes, sus retratos mágicamente reveladores del carácter, sus desnudos de mujer que tienen un dinamismo estilizado, no sin relación con la escultura egipcia, hacen de él el más grande fotógrafo que haya vivido. Y si esto es así, es importante que en nuestra tierra de máquinas, nuestra tierra selva de máquinas, el hombre de sensibilidad más profunda, de visión más personal, quizás, haya elegido una cámara fotográfica, -una máquina- para expresar su visión. Stieglitz no es un filósofo. Pero, con todo, si un verdadero Nuevo Mundo nace en América, los filósofos discutirán la significación metafísica de Alfred Stieglitz. Sin embargo, mis pensamientos están hoy con él, no como el artesano cuya humildad 
particularmente esas obras, primero, por ser testimonio de ceremonias en peligro de extinción, dramas dancísticos en los cuales se imitan los actos de los seres sagrados que auxilian y sustentan a los hombres, donde el indio pueblo surge "como artista de una pantomima simbólica" sin parangón sobre el planeta. A diferencia del "pintor americano o del europeo", quienes pintan "el fenómeno", consignando las sensaciones visuales, el "indio se concentra en la cosa misma (...) El indio consigna lo que él sabe, corrigiendo su visión por medio de su conocimiento y de su comprensión instintiva".

Más tarde, en 1934, Cahill colabora en el catálogo de la exposición de Arshile Gorky, para las Galerías Mellon de Filadelfia, junto a otros artistas conceptuales como Frederick Kiesler y Stuart Davis, y en los años '50, llegó a reseñar para la New York Times Book Review dos obras de alguien vinculado al surrealista Wolfgang Paalen, el pintor mexicano Miguel Covarrubias, The Eagle, the Jaguar, and the Serpent. Indian Art of the Americas (1954) e Indian Art of Mexico and Central America (1957). Se trata de peculiares experiencias de anacronismo que, en el sur, serían intentadas, incluso, por Lucio Fontana, quien creía que los hombres prehistóricos, al percibir, por primera vez, un sonido producido por golpes dados sobre un cuerpo hueco, se sintieron subyugados por esas combinaciones rítmicas, al punto de transformar al arte en una cuestión de toque y contacto, ${ }^{9}$ algo en sintonía con las experiencias de John Cage, en Totem Ancestral (1943), Tierra Espontánea (1944) o Música para Marcel Duchamp (1947).

Cahill comprende pues, en la cosa misma, la unidad de la cultura indígena, entendida como una vida estética y religiosa integradas a la naturaleza. Aludiendo a "algunas de las lenguas indígenas", que sólo cuentan con una palabra para describir la felicidad y la belleza, Cahill coloca este hecho frente al mundo contemporáneo,

ante el hecho ha producido milagros (sólo el amor -cuyo otro nombre es humildad- hace milagros): sino como el Sócrates americano que ha nutrido a toda una generación de pintores, escritores, hombres y mujeres creadoras. Digo: nutrido, y no mimado. Este hombre ha sido duro y despiadado. Muchas veces, en los tiempos idos, fuí a él, angustiado, buscando consuelo. Nunca encontré el consuelo; obtuve, en cambio, una visión de la verdad que curaba el egoísmo de mi angustia". Cf Frank, Waldo. Ustedes y nosotros: Nuevo mensaje a Ibero-América. Buenos Aires: Losada, 1942, 146-147).

${ }^{9}$ Cf. Fontana, Lucio: "Manifiesto Blanco" in Cipollini, Rafael: Manifiestos argentinos. Política de lo visual. Buenos Aires, Adriana Hidalgo, 2003, 192. 
descripto, en un arrebato crítico, como un "sórdido Babel industrial", producto del "Pueblo de la Máquina", que ha llevado lo feo a su apoteosis. Su propuesta estética, el inje-inje, no pasaría pues de una imitación performativa pautada por el esfuerzo de emplear elementos amerindios para la estética de la vanguardia que compartía con sus colegas, George Bellows, Max Weber, Mark Tobey, Walt Kuhn, Jules Pascin, Joseph Stella y William Zorach. Cahill, como dije, ubica esa experiencia del inje-inje en torno a 1920:

\begin{abstract}
En esa época, como saben, muchos de nosotros estábamos muy interesados en el arte precolombino. Yo solía recorrer el Museo de Historia Natural, y ahí tenía un amigo especial, el doctor Mead, el curador de lo peruano. De haberse realizado alguno de nuestros conciertos, él me iba a prestar la flauta de percusión, un instrumento curioso hecho de bambú, partido en uno de sus extremos, de origen filipino, y también algunos gigantescos tambores de señales africanos. ${ }^{10}$
\end{abstract}

Aunque el motivo de esta búsqueda de las "cualidades abstractas", como decía Cahill, absolutamente panculturales y panhistóricas, no parece trascender el eclecticismo de la cultura art-nouveau, las cuestiones sociales, históricas y culturales provocadas por el primitivismo modernista, son, no obstante, innegables consecuencias de este proceso de amplia transculturación estética. ${ }^{11}$ Waldo Frank, uno de los mentores indirectos de Cahill, había construido sus relatos de City Block (1922) según la tensión entre el yo innato y el yo adquirido, la persona y el ambiente,

\footnotetext{
${ }^{10}$ Apud Moore, Alan W.: "Holger Cahill y el inje-inje. La historia del primitivismo modernista," op. cit., 85-112. Según Moore, Charles W. Mead, el curador de lo incaico en el Museo de Historia Natural, pudo haber colaborado de manera significativa en el inje-inje de Cahill. Mead promovió fuertemente las colecciones de objetos peruanos del Museo, tanto entre los artistas como con el público. Cf. Eberle, Louise: "Peruvian Tapestries that Surpass Gobelins", New York World, "Sunday Magazine", 20 feb. 1921, 5; Einstein, Carl: "Tapeçaria peruana da coleção Gans" (1922) in ANTELO, Raul: "Carl Einstein: a construção de uma realidade mitológica" in Crítica Cultural, Vol. 3, No 1, Florianópolis, ene.- jun. 2008.

${ }^{11}$ Cahill es, en ese sentido, pionero del "primitivismo" en el arte moderno. Ver, a ese respecto, Goldwater, Robert: Primitivism and Modern Art, Belknap/Harvard, 1966 (1 $1^{\text {a }}$ edición, 1938); Rubin , William (ed.): "Primitivism" in 20 th Century Art, Nueva York, Museo de Arte Moderno, 1984; Rhodes, Colin: Primitivism and Modern Art, Londres, Thames \& Hudson, 1994; Clifford, James: The Predicament of Culture: Twentieth-Century Ethnography, Literature, and Art. Cambridge, Harvard, 1988.
} 
lo que aproximaba a Frank a narradores como Sherwood Anderson o Hemingway. ${ }^{12}$ Pero esa misma división subjetiva explicaba igualmente la fascinación de Frank por procesos amerindios soberanos de fusión. ${ }^{13}$ Esa tensión nos muestra, además, que la estética inje-inje se basaba, según Moore, en lo que parecía ser una etnografía fantástica de base lingüística real. De forma semejante a la de Ana Cristina César, que, en Correspondencia Completa (1979), incluye una única carta:

Inje-inje, una lengua de una sola palabra, ubica esencialmente a un pueblo amerindio en el silencio, desplazado del habla, del discurso, en un dominio de pura presencia física, "la cosa en sí". El teatro que Cahill (...) derivó de los injes fue la pantomima, y así la describe él. "Una de nuestras reglas para el teatro era que las caras y las manos debían estar enmascaradas pues ellas ya habían aprendido mucho sobre las mentiras. Sólo debian estar expuestas las partes más voluminosas del cuerpo" (...). "La idea de las máscaras en las representaciones dancísticas y teatrales (una máscara

${ }^{12}$ Es la opinión de Luis Saslavsky, que años más tarde filmaría un pastiche de travestimiento como Vidalita o una ficción Unheimliche como Las ratas, basada en la novela de Pepe Bianco. Cf. Saslavsky, Luis: "El cuentista Waldo Frank" in Síntesis, № 29, Buenos Aires, oct. 1929, 131-2. En esa misma ocasión, la gran amiga de Saslavsky, Maria Rosa Oliver, traduce para Síntesis "Accolade" y "Esperanza", dos relatos de City Block.

${ }^{13}$ En su clásico América Hispánica, dice Frank que "filhos do Sol, os incas se tornaram absolutos na sua outorga das leis do Sol. Nenhum dirigente desrespeitou essas leis, cujos verdadeiros intérpretes e expositores eram os amuatas. $O$ ayllu dos incas era sujeito a uma impiedosa disciplina do espírito e do corpo, a qual recorda os Brâmanes e os pitagóricos. O jovem que fraquejava era degradado. Ser Filho do Sol significava estar perpètuamente prêso como o próprio Sol. E tão raramente as pessoas desrespeitavam as leis, que crimes individuais se tornaram históricos; em todos os anais de Tahuantin-suyu, não há exemplo de uma virgem inca, dedicada ao Sol, ter fugido à virtude. Dia a dia, o Sol perfazia o seu ciclo; e a gente ligada ao Sol não imaginava atos em desacôrdo com a cadência dêle. Contudo havia liberdades permitidas por lei: a embriaguez parece ter sido costumeira em tôdas as festas e o canto e a dança irradiavam da vida comunal como os raios se desprendem do sol. $O$ segrêdo dessa cadência universal encontra-se no fato decisivo de que a vontade pessoal era instintivamente transfigurada pela aceitação instintiva do ayllu como a unidade do eu. Um grupo não pode fazer mal a si mesmo; só o grupo que se julga separado de outros ou que é dirigido por um homem que se sente separado dêle pode cair em desvario. Mas êsses grupos, desde o mais humilde ayllu sob o seu curaka até Tahuantin-suyu sob o seu inca universal compunham-se de homens e eram dirigidos por homens que se sentiam não pessoas no sentido europeu de almas porém meras cargas elétricas do ayllu. E o ayllu sentia-se uma função de Tahuantin-suyu; e o império sabia que era um esbôço do ayllu. Por isso embora o inca fôsse o senhor supremo era o oposto do monarca, sendo o foco articulado do povo. Cf. Frank, Waldo. América hispânica. Trad. Anna A. de Queiroz Carneiro de Mendonça. Rio de Janeiro: Casa do Estudante do Brasil, 1946, 74-75. 
blanca para la cara, una especie de mitones-máscara-no-guantes para las manos) era que la cara y las manos ya habian sido muy usadas para una expresividad remilgada y sin sentido y hasta falsa y que el bailarín y el actor dependan más de las partes masivas del cuerpo, las cuales, al igual que la tierra, no ofrecen respuestas falsas" (1950). La idealización que hace Cahill de lo primitivo se basa en la búsqueda de la verdad. Él no buscaba principios universales de dibujo, como Arthur W. Dow o Jay Hambidge, sino variedades de expresión universales en un pastiche ideal primitivo. (Moore, 2005) $)^{14}$

El primitivismo performativo y la teatralización de la etnicidad reconciliaban así, a los ojos de Cahill, la figura del poeta con el histrión, es decir, lo filiaban a la tradición teatral de la canción cómica y del teatro de revista, géneros fuertes en Estados Unidos. Aunque tanto los espectáculos locales de mímica, cuanto el vaudeville, de abierta raigambre europea, pronto entrarían en decadencia, es innegable que las dinámicas de identificación étnica se incorporaron, sin embargo, a la música del jazz y al cine, acaparados por Al Jolson e Irving Berlin, incorporando, efectivamente, el habla afroamericana, retrabajada, a su vez, en la literatura, por escritores como Ezra Pound, T. S. Eliot y Gertrude Stein. En Argentina esto también se manifiesta sintomáticamente en una película como Embrujo (1941), basada en la novela histórica A Marquesa de Santos, de Paulo Setúbal, en que Enrique Susini, fundador de Radio Municipal y autor de un clásico como Los tres berretines, no duda en escalar al cantor cubano Bola de Nieve para interpretar al criado Chalaça, ni ponerlo a cantar, en una taberna paulista decimonónica, un aire que no es otra cosa sino un poema afro-cubano de Songoro-cosongo, el libro de Guillén. ${ }^{15}$ No nos olvidemos tampoco que en los salones de Amigos del Arte, en la calle Florida, era

\footnotetext{
${ }^{14}$ Alan Moore interpreta que, lingüísticamente, "inje-inje" es una solución reduplicativa, un eco, como "dadá", "ismism" y muchos otros que dan color al lenguaje de los años 1920. Otros, como "choo-choo" o "fuck-fuck", aparecen en el lenguaje infantil y en el inglés champurreado usado en China, según explican Wentworth \& Flexner en su Dictionary of American Slang. Inje desde luego remite a Injun, una palabra con rica historia en el slang de Estados Unidos y que equivale a un juramento de honestidad, "honest Injun!", a una expresión de ira, como en "get up one's injun" y a una expresión de sinceridad hacia los principios "Injun Here!".

${ }^{15}$ Embrujo. Director: Enrique T. Susini. Producción: Lumiton Cinematografica. Argumento: Enrique T. Susini y Pedro Miguel Obligado. Música: George Andreani. Coreografía: Maria Ruanova. Intérpretes: Georges Rigaud (D. Pedro), Alicia Barrié (Domitila de Castro), Pepita Serrador, Ernesto Vilches, Santiago Gómez Cou, Carlos Tajes, Maria Ruanova, Amery Darbon, Pablo Donadio, Carlos Bouhier, Pablo Lagarde y Bola de Nieve.
} 
posible oír, por esa época, tanto el cuarteto de laúdes de los hermanos Aguilar, como la música atonal del grupo Renovación o la voz de la cantante francesa Jane Bathori, íntima de Satie o Debussy, junto a algunas experiencias de music-hall, recitales de música negra en la voz de Blackie o tangos arrabaleros cantados por Olinda Bozán o Azucena Maizani. ${ }^{16}$ Allí mismo, en los salones de Van Riel, María Dalbaicín -bailarina que se integrara a la troupe de Diaghilev tras la salida de Massine, aportando la sensualidad de su Cuadro flamenco (1921), retratada por Picasso, y que trabajara, además, entre otras películas, en Surcouf, con Antonin Artaud- organizó una serie de bailes, "Una tarde española", "Una tarde vasca", "Una tarde criolla" y "Una tarde peruana". También la cantante paulista Germana Bitencourt, casada con el poeta martinfierrista Pedro J. Vignale, ofreció allí mismo recitales de música brasileña, que se sumaron al concierto vocal de la Sociedad Cultural de Conciertos, dirigida por Gastón Poulet, o a los poemas de Baudelaire, recitados por Victoria Ocampo.

La experiencia social del baile estaba pues íntimamente ligada a los actos de vanguardia. En Brasil son famosas las fiestas de carnaval promovidas por la Sociedad de Protección al Arte Moderno (SPAM), cuyos salones eran decorados por artistas como Lasar Segall y alabados por Mário de Andrade. Este mismo llegó a componer un poema para el baile carnavalesco "A cidade de SPAM", cuyos escenarios eran de Lasar Segall. Dice el poeta:

\section{E se abre a farra fanfarrã! \\ Doutores, mendigos, exóticas \\ Pernas, carruagens estrambóticas \\ Barcarolas a rataplã, \\ Heróis nascidos na antevéspera \\ Jogadores de box e víspora,}

\footnotetext{
${ }^{16}$ Opuesta a la de los Amigos del Arte era la estética de un cronista mundano como Juan José de Soiza Reilly, redactor del Hogar que, como nos informa Verónica Meo Zilio, escribió un extenso artículo denostando "La cultura chic en Buenos Aires. Asociaciones protectoras del arte que terminan en casa de juego o en algo peor", en que auguraba que Amigos del Arte "una vez que obtenga su personería jurídica, empezará a mostrarse tal cual es. Ya nos imaginamos que en sus bellos salones se jugará a las cartas. Al treinta y cuarenta. Ruletita. Timba... Después se pondrá una jazz-band. Mesitas en cuadro. Bailes de cultura 'chic'. Y gracias a la miseria de los artistas, la institución podrá convertirse en un aristocrático cabaret con anexos donde algunas señoras y niñas de cultura 'chic' irán como antes iban a las casas de moda".
} 
Esporas, cascos, besta ruã...

E a fauna urbana e suburbana

Dançando o fox, o quero-mana

Corda bamba, valsa alemã

Samba, tango, jongo e bolero!

Vinde ver isso ao Trocadero

Na carnavalada do SPAM! (Andrade, 2000:551)

Había, por otro lado, las reuniones más iconoclastas del Club de Artistas Modernos, capitaneado por Flávio de Carvalho, pero tal como la exposición de la Sociedad de Artistas Independientes, el baile en el medio artístico era reflejo de modelos europeos, a la usanza del Baile del Quat'z Arts, la festividad anual de los estudiantes de arte de París. El impulso hacia el disfraz, en esas alocadas mascaradas, estuvo siempre presente en la vida social de los artistas de vanguardia. Artistas blancos con la cara pintada de negro fueron parte de los eventos dadaístas en Europa. Philippe Soupault apareció como artista de circo con la cara pintada de negro, en París, en la primavera de 1920 y se presentó al Salón Dadá, al año siguiente, disfrazado como el presidente de Liberia. En 1919, George Grosz se pintó de negro e imitó el acento afro como maestro de ceremonias en un evento dadá en Berlín. Y en las sesiones de Amigos del Arte Ramón Gómez de la Serna hizo lo propio con el rostro cubierto por betún. Esa tan explícita identificación de la vanguardia con los colonizados se suele interpretar como "negrofilia", le tumulte noir, la locura europea por el jazz de Estados Unidos y el amor por la escultura africana. ${ }^{17}$

Pues no se puede ignorar que fue entre los indios pueblo, o para ser más exacto, en una danza ritual de esos aborígenes, la danza de la serpiente, que, poco antes del descubrimiento de Edgar L. Hewett, Robert Henri o John Sloan, Aby

${ }^{17}$ Cf. Zayas, Marius de: Cómo, cuando y por qué el arte moderno llegó a Nueva York. Estudio introductorio y traducción Antonio Saborit. México, Universidad Nacional Autónoma de México, 2005; Einstein, Carl: "Negerplastik" in Qu'est-ce que la sculpture moderne? Paris, Centre Georges Pompidou, 1986, 344-353; Idem: La escultura africana. Barcelona, Gustavo Gili, 2002. Incluye "Escritos de Carl Einstein sobre arte africano", de Liliane Meffre; "La escultura negra" (1915), el ensayo de Carl Einstein; "Notas sobre un torso", por E. Bassant y J.-L. Paudrat; y dos ensayos de Carl Einstein, "La escultura africana" y "A propósito de la exposición de la Galería Pigalle". Una derivación de ello es la reflexión sobre la máscara aborigen. Cito tan sólo una contribución póstuma, "Iconology and the Masking Complex in Eastern North America", que recoge las observaciones de uno de los más brillantes discípulos de Franz Boas, Frank G. Speck, publicada en Filadelfia (University Museum Bulletin, The University of Pennsylvania, Vol. 18, № 1, jul. 1950). 
Warburg encontraría la mitología (Mnemosyne) para escapar del mito evolucionista (el factum) de la cientificidad y del tiempo pleno. La salida, a su juicio, sería la de una causalidad bailada, de estirpe dionisíaca, girando en torno al vacío de sentido del sentido.

Mucho más tarde, al comentar La Fábula mística de Michel de Certeau, Jacques Derrida aludiría a esa danza de los significantes en torno al sí:

\begin{abstract}
Supposons un premier oui, le oui archi-originaire qui avant tout engage, promet, acquiesce. D'une part, il est originairement, dans sa structure même, une réponse. II est d'abord second, venant après une demande, une question ou un autre oui. D'autre part, en tant qu'engagement ou promesse, il doit au moins et d'avance se lier à une confirmation dans un prochain oui. Oui au prochain, autrement dit à l'autre oui qui est déjà là mais reste pourtant à venir. Le "je" ne préexiste pas à ce mouvement, ni le sujet, ils s'y instituent. Je ("je") ne peux dire oui (oui-je) qu'en promettant de garder la mémoire du oui et de le confirmer aussitôt. Promesse de mémoire et mémoire de promesse. Ce "deuxième" oui est a priori enveloppé dans le "premier". Le "premier" n'aurait pas lieu sans le projet, la mise ou la promesse, la mission ou l'émission, l'envoi du second qui est déjà là en lui. Ce dernier, le premier, se double d'avance: oui, oui, d'avance assigné à sa répétition. Comme le second oui habite le premier, la répétition augmente et divise, partage d'avance le oui archi-originaire. Cette répétition, qui figure la condition d'une ouverture du oui, le menace aussi: répétition mécanique, mimétisme, donc oubli, simulacre, fiction, fable. Entre les deux répétitions, la "bonne" et la "mauvaise", il y a à la fois coupure et contamination. "Cruelle quiétude", cruel acquiescement. Le critère de la conscience ou de l'intention subjective n'a ici aucune pertinence, il est lui-même dérivé, institué, constitué. (Derrida, 1987)
\end{abstract}

Promesa de memoria y memoria de la promesa, el segundo sí, el segundo inje, debe ser un renovamiento absoluto, inaugural y libre de energías, una auténtica ruptura antropofágica, de suerte que el segundo inje rompe con el primer inje, tal como el mismo Derrida nos lo demuestra en "Ulises gramófono".

La repetición del oui puede tomar formas mecánicas, serviles, que a menudo doblegan a la mujer ante su amo; pero no es por accidente, aun si toda respuesta a otro como otro singular, parece, debe escapar a eso. El sí de la afirmación, del asentimiento o de sentimiento, de la alianza, del compromiso, de la firma o del don debe llevar la repetición en sí mismo para valer lo que vale. Debe confirmar inmediatamente y a priori su promesa y prometer su confirmación. Esta repetición esencial se deja asediar por la amenaza intrínseca, por el teléfono interno que la parasita como su doble mimético-mecánico, como su parodia incesante. Regresaremos a esta fatalidad. Pero ya escuchamos esta gramofonía que registra la escritura en la voz más vivaz. Ella la reproduce a priori, en ausencia de toda presencia intencional del afirmador o la afirmadora. Tal gramofonía ciertamente responde al sueño de una reproducción que guarda, como su verdad, el sí viviente, archivado en su más viva voz. Pero por eso mismo, da lugar a la 
posibilidad de una parodia, de una técnica del sí que persigue el deseo más espontáneo y más dador del sí. Este, para responder a su destino, debe reafirmarse inmediatamente. Así tal es la condición de un compromiso firmado. El sí no puede decirse a menos que se prometa la memoria de sí. La afirmación del sí es afirmación del la memoria. Sí debe conservarse, o sea reiterarse, archivar su voz para volverla a dar a oír. Es lo que llamo el efecto de gramófono. Sí se gramofonea y se telegramofonea a priori. El deseo de memoria y el luto del sí ponen en marcha la máquina anamnésica. Y su aceleración hipermnésica. La máquina reproduce lo vivo, lo duplica con su autómata. (Derrida, 2002:74-75) ${ }^{18}$

Ese efecto de la máquina gramofónica, como la llama Derrida, está presente, como señalábamos antes, en los trabajos de Warburg. José E. Burucúa, gran estudioso argentino de la obra de Warburg, recuerda que ese método sufrió, entre 1933 y 1948, un cierto congelamiento humanista, una súbita autonomización, cuando Fritz Saxl buscó ampliar el registro de las Pathosformeln de la civilización europea e incorporó a esa serie creada por Warburg la figura del varón que lucha contra el animal, la figura del sufriente y la del mensajero celeste. De allí en más, la vida de las Pathosformeln se convirtió en vida de simples imágenes y la descripción pasional de sus avatares históricos se degradó en un mero itinerario iconográfico. Es decir que...

${ }^{18}$ Cf. Derrida, Jacques. Ulises gramófono. Dos palabras para Joyce. Trad. Mario E. Teruggi. Buenos Aires: Tres Haches, 2002, 74-75. En "Nietsche y la máquina", Derrida reitera que "There is a time and a spacing of the 'yes' as 'yes-yes': it takes time to say 'yes'. A single 'yes' is, therefore, immediately double, it immediately annouces a 'yes' to come and already recalls that the 'yes' implies another 'yes'. So, the 'yes' is immediately double, immediately 'yes-yes'. This immediate duplication is the source of all possible contamination... The second 'yes' can eventually be one of laughter or derision at the first 'yes', it can be the forgetting of the first 'yes'... With this duplicity we are at the heart of the 'logic' of contamination. One should not simply consider contamination as a threat, however. To do so continues to ignore this very logic. Possible contamination must be assumed, because it is also opening or chance, our chance. Without contamination we would have no opening or chance. Contamination is not only to be assumde or affirmed: it is the very possibility of affirmation in the first place. For affirmation to be possible, there must always be at least two 'yes's'. If the contamination of the first 'yes' by the second is refused -for whatever reasons- one is denying the very possibility of the first 'yes'. Hence all the contradictions and confusion that this denial can fall into. Threat is chance, chance is threat -this law is absolutely undeniable and irreducible. Iff one does not accept it, there is no risk, and, if there is no risk, there is only death. If one refuses to take a risk, one is left with nothing but death." Derrida, Jacques. "Nietzsche and the Machine". Trans. R. Beardsworth. In: Negotiations: Interventions and Interviews, 1971-2001, ed. E. Rottenberg, Stanford, University Press, 2002, 247248. 
...el método trágico de Warburg, trágico debido al desgarramiento que produce una construcción historiográfica tensada entre lo universal de una categoría, por más históricamente determinada que se la considere, y lo particular, individual y fragmentario de sus concreciones reales sucesivas, se transformó en un apaciguado método iconográfico merced a Saxl y, mucho más todavía, a los trabajos de Erwin Panofsky.

Por eso Burucúa se impuso la tarea de "retomar el camino abierto por Aby Warburg e intentar hacer el repertorio de las Pathosformeln que han tejido y tejen todavía la experiencia cultural y civilizatoria de quienes nos tenemos por sucesores de la modernidad euroatlántica". Porque esas formas representativas y significantes, auténticos vectores de una constelación emocional, son "las intermediarias necesarias en todo proceso de pasaje o transferencia entre las esferas de lo racional-tecnológico y lo mágico que, según la teoría histórica de la cultura de Aby Warburg (replicada en este sentido por la teoría antropológica general de Bronislaw Malinowski), es el prototipo de cualquier práctica de permanencia o de cambio cultural", con lo cual, apoyado en Warburg, Burucúa nos está diciendo que toda lectura descansa...

\begin{abstract}
...casi exclusivamente en los términos de los conflictos, conciliaciones, coexistencias y combates entre la ratio de la iluminación científica, asociada al dominio técnico de la naturaleza, y la comprensión analógica que nos conduce a creer en una unidad mágica y consoladora del mundo, más allá del principio de no contradicción. Las Pathosformeln, llevadas a la plenitud de su intensidad significante y emocional en el plano de la estética, serían así los eslabones que, aun en los momentos de lucha más encarnizada entre los hombres tecnológicos y los hombres mágicos (...) o bien en los momentos de derrumbe de los sistemas racionales que provocan las grandes crisis de la economía y de la sociedad, salvan y hacen posible la comunicación mínima entre el logos y las analogías emocionales, la relación que preserva la unidad y la continuidad de la vida humana o de la cultura.
\end{abstract}

De lo cual se desprende que, para Burucúa, una Pathosformel es...

...un conglomerado de formas representativas y significantes, históricamente determinado en el momento de su primera síntesis, que refuerza la comprensión del sentido de lo representado mediante la inducción de un campo afectivo donde se desenvuelven las emociones precisas y bipolares que una cultura subraya como experiencia básica de la vida social. Cada Pathosformel se transmite a lo largo de las generaciones que construyen progresivamente un horizonte de civilización, atraviesa etapas de latencia, de recuperación, de apropiaciones entusiastas y metamorfosis. Ella es un rasgo fundamental de todo proceso civilizatorio históricamente singular. (Burucua, 2006:12-13) 
Tanto en la obra de Roberto Calasso, ${ }^{19}$ como en la de Giorgio Agamben ${ }^{20}$ o Georges Didi-Huberman, ${ }^{21}$ hay um evidente retorno a esos postulados dinámicos warburguianos, pero es alguien que viene del cine, Philippe-Alain Michaud, quien, quizás, haya mostrado más cabalmente, en el montaje warburguiano, en su máquina mitológica, los primeros pasos de las histoire(s) o pasajes que podemos proponer a partir de los lindes de experiencia y memoria. ${ }^{22}$

Por todo ello, en este punto, cabría retomar la distinción entre mito y mitología que Furio Jesi nos planteaba al principio. O mejor, repensarla a la luz de una relectura muy sintomática, la de Giorgio Agamben. Reconociendo en Jesi un precursor, alguien que no se adaptó al magro dualismo de la posguerra, dilacerado entre racionalidad/irracionalidad, historia/mito, religión/laicismo, derecha/izquierda, Jesi que, según Agamben, diseña la cartografía imaginaria de un territorio limítrofe -los lindes- entre historia y mito, tiene en sus manos un dispositivo -un talismáncon el que condensa sus "pensamientos secretos", reanudando aporías y paradojas, que no son sólo teóricas, sino abiertamente políticas. La más emblemática, nos dice Agamben, es la tensión entre rebelión y revolución, entre la experiencia de suspensión del tiempo histórico y la de introducir en el tiempo histórico un determinado orden. Eso nos lleva a entender que la sociedad contemporánea, a través del control, no persigue disciplinar el orden, sino crear un desorden que

${ }^{19}$ Cf. Calasso, Roberto: La follia che viene dalle Ninfe, Milano, Adelphi, 2005.

${ }^{20}$ Cf. Agamben, Giorgio: Ninfe. Torino, Bollati Boringhieri, 2007; Idem: Image et mémoire. Paris, Hoëbeke, 1998.

${ }^{21}$ Cf. Didi-Huberman, Georges: L 'image survivante. Histoire de l'art et temps des fantômes selon Aby Warburg. Paris, Minuit, 2002; IDEM - Ninfa moderna. Essai sur le drapé tombé. Paris, Gallimard, 2002; Idem: Ante el tiempo. Historia del arte y anacronismo de las imágenes. Trad. O. Oviedo Funes. Buenos Aires, Adriana Hidalgo, 2005; Idem: Imágenes pese a todo. Memoria visual del Holocausto. Trad. M. Miracle. Barcelona, Paidós, 2004; Idem: La imagen mariposa. Barcelona, Mudito and Co, 2007. Sobre el autor, consultar Zimmermann, Laurent (ed.): Penser par les images. Autour des travaux de Georges Didi-Huberman. Nantes, Editions Cécile Defaut, 2006.

${ }^{22}$ Cf. Michaud, Phillippe-Alain: Aby Warburg and the Image in Motion. Trans. S. Hawkes. Foreword by G. Didi-Huberman. New York, Zone Books, 2007. 
justifique la presencia omnímoda de la vigilancia. ${ }^{23}$ Véase cuán lejos estamos de la bienpensante y evolutiva teoría de lo moderno de Octavio Paz, con su naturalización de la revolución, al precio de desactivar la rebelión.

Muy por el contrario, Jesi busca activar la máquina mitológica, que es una forma de confrontar "este mundo" con el "otro mundo", mostrando que el mito no tiene sustancia, no posee materia, sino que es un pliegue, un modo de acción de la máquina mitológica -el lenguaje, las instituciones, la creencia que las sustenta-. El ser o no ser se muestra así impotente en el presente. La cuestión que atañe a los lindes de la cultura, en cambio, consiste en conocer la potencia de la tensión que ella misma puede desplegar entre mito y mitología, entre lo pre-existente y lo exsistente, es decir, generar la diferencia inherente al propio ser.

Jesi, muy influido por el generatismo institucional de Humboldt, llega a decir que toda lengua diseña, en torno al pueblo que la habla, una suerte de círculo mágico, que la protege del riesgo de entrar en el círculo de otra lengua y de otro pueblo. No hay pues valor intrínseco. Todo valor sólo revela una fuerza. No es una forma. No se lo puede leer autónomamente. Así, el inje-inje fue, para Cahill, un laboratorio maccarthista pero, para Huidobro, funcionó como seminal laboratorio concretista. "Il mito è questo cerchio magico e la sfera delle cose che ci non-sono con cui esso s'identifica è quella che il linguaggio umano incessantemente produce e presuppone nel suo cuore di non-essere" -nos resume Agamben- y esa observación robustece el previo análisis de Jesi, para quien el vacío -la disponibilidad, el lenguaje- es quien, a rigor, habita la máquina mitológica.

L'una e l'altra, del resto, la rivolta e la rivoluzione, non contraddicono a livello concettuale il modello proposto dalla macchina mitologica. Anzi: nella prospettiva aperta sia dall'una sia dall'altra, codesto modello finisce per identificarsi con l'a priori che resta quale fondamento solido e oscuro del processo gnoseologico. Di fronte all'essenza del luogo comune -o all'essenza del mito- non vi è autentica alternativa concettuale, bensi soltanto alternativa gestuale, di comportamento, ma di comportamento che resta comunque circoscritto entro la scatola delimitata dalle pareti della macchina mitologica. Rivolta e rivoluzione, al livello concettuale, restano null'altro che diverse articolazioni (sospensioni del tempo; tempo "giusto") del tempo che vige all'interno di quella scatola. (Jesi, 1996:30-31)

\footnotetext{
${ }^{23}$ Es la tesis foucaultiana defendida por Agamben en respuesta a la visión funcional de Bauman. Cf. Bauman, Zygmunt: Archipiélago de excepciones. Comentarios de Giorgio Agamben y debate final. Buenos Aires, Kats, 2008.
} 
La idea, obviamente, no se agota en Rimbaud. Es inherente a la poesía y podemos reconocerla, mucho antes del inje-inje, en la suma desnudez o la noche oscura de San Juan de la Cruz. ${ }^{24}$ Según Agamben, en este punto, auténtico linde de su misma subjetividad, el crítico contempla, por un instante, en una suerte de "disincantata divinazzione", el auténtico aleph de una modernidad sin centro ni materia, absolutamente posautonomizada.

Giunto a questo limite, señala, conclusivamente, Agamben, in cui il cuore della macchina coincide con la sua stessa esistenza, il mitologo -o podríamos decir, incluso, el crítico de las ficciones- deve deporre i suoi strumenti. L'esistenza e la non-esistenza della macchina coinvolgano ora la sua strategia vitale, si decidono alle frontiere dello stesso linguaggio. ${ }^{25}$

${ }^{24}$ En su prefacio a las Poesias de San Juan de la Cruz, Agamben señala que "il paradosso della teologia mistica è appunto questo: che, in quanto è opacità e spossessamento integrale, l'espererienza finale che essa implica è quella, puramente negativa, di una presenza che non si distingue in nulla da un'assenza; in senso proprio, essa non è anzi una teologia (una scienza di Dio), ma una teo-alogia, che approda a un'inconoscibilità ultima, o, almeno, a un conoscere soltanto per opacamento e negazione, a un'appropriazione il cui oggetto è l'Inappropriabile stesso, e che non è, perciò, sostanziabile in un habitus dottrinale positivo, ma soltanto metaforizzabile e alludibile per ossimori, catacresi a altre 'figure e similitudini stravaganti". Esta idea que reaparecerá en su obra más reciente (recordemos la definición de poesía moderna, en El poder y la gloria, como teo-alogía) le lleva a señalar la concomitancia entre el poeta español y un pensador como Georges Bataille que, en su Somme athéologique, nos revela la deuda con el precursor, no sólo en conceptos como la nudité souveraine de uno y la suma desnudez del otro, el non-savoir de Bataille y el saber del poeta místico. Éste mismo nos habría mostrado, dice Agamben, a través de la experiencia interior, la opacidad del mal, razón por la cual San Juan podría ser leído como fundador del linaje de la potencia pasiva o potencia de lo negativo que, dos siglos más tarde, sería enunciada por Hegel, quien la situaría en el centro de su sistema, como auténtico "poder mágico". Cf Agamben, Giorgio: "La 'notte oscura' di Juan de la Cruz" in CRUZ, San Juan de la: Poesie. Trad. Giorgio Agamben. Torino, Einaudi, 1974, VI-VII. Para desarrollos más recientes de esas ideas, consultar, del mismo autor, La potencia del pensamiento (Buenos Aires, Adriana Hidalgo, 2007) o II sacramento del linguaggio. Archeologia del giuramento (Bari, Laterza, 2008).

${ }^{25}$ Agamben, Giorgio: "Il talismano di Furio Jesi" in JESI, Furio: Lettura del "Bateau ivre" di Rimbaud, op. cit., 8. 


\section{Bibliografía}

Agamben, G. (2008): II sacramento del linguaggio. Archeologia del giuramento. Laterza, Bari.

(1998): Image et mémoire. Hoëbeke, Paris.

(1974): "La 'notte oscura' di Juan de la Cruz", en Poesie, CRUZ, S. J. Einaudi, Torino. (Traducción de Giorgio Agamben).

(2007): La potencia del pensamiento. Adriana Hidalgo, Buenos Aires. (2007) Ninfe. Bollati Boringhieri, Torino.

Andrade, M. (2000): “A cidade do SPAM”, en Correspondência Mário de Andrade \& Manuel Bandeira, Marcos Antônio de Moraes (ed.). Edusp, São Paulo.

Bauman, Z. (2008): Archipiélago de excepciones. Comentarios de Giorgio Agamben y debate final. Kats, Buenos Aires.

Benjamin, W. (2002): “Johann Jakob Bachofen", en Selected writings, Michael Jennings (ed.). Belknap, Harvard, 11-24.

Burucúa, J. E. (2006): Historia y ambivalencia. Ensayos sobre arte. Biblos, Buenos Aires.

Cahill, E. H.: "America Has Its 'Primitives': Aboriginal watercolorists of New Mexico make a faithful record of their race", en International Studio, marzo 1922, Vol. $75, \mathrm{~N}^{\circ}$ 299, 80-83.

(1957): H. Entrevista concedida al programa de Historia Oral de Columbia University, Nueva York.

Calasso, R. (2005): La follia che viene dalle Ninfe. Adelphi, Milano.

Clifford, J. (1988): The Predicament of Culture: Twentieth-Century Ethnography, Literature, and Art. Cambridge, Harvard.

Derrida, J. (2002): "Nietzsche and the Machine" en Negotiations: Interventions and Interviews, 1971-2001, E. Rottenberg (ed.), R. Beardsworth (trans.). University Press, Stanford.

(1987): "Nombre de oui". "Michel de Certeau”, en Cahiers pour un temps. Paris. 
(2002): Ulises gramófono. Dos palabras para Joyce. Tres Haches, Buenos Aires. (Traducción de Mario E. Teruggi).

Didi-Huberman, G. (2005): Ante el tiempo. Historia del arte y anacronismo de las imágenes. Adriana Hidalgo, Buenos Aires. (Traducción de O. Oviedo Funes).

(2004): Imágenes pese a todo. Memoria visual del Holocausto. Paidós, Barcelona. (Traducción de M. Miracle).

(2002): L 'image survivante. Histoire de l'art et temps des fantômes selon Aby Warburg. Minuit, Paris.

(2007): La imagen mariposa. Mudito and Co, Barcelona.

(2002): Ninfa moderna. Essai sur le drapé tombé. Gallimard, Paris.

Eberle, L.: "Peruvian Tapestries that Surpass Gobelins", en New York World, "Sunday Magazine", 20 feb. 1921.

Einstein, C. (2002): La escultura africana. Gustavo Pili, Barcelona.

(1986): "Negerplastik", en Qu'est-ce que la sculpture moderne?. Centre Georges Pompidou, Paris, 344-353.

(1922) "Tapeçaria peruana da coleção Gans". ANTELO, R. "Carl Einstein: a construção de uma realidade mitológica”, en Crítica Cultural, ene.- jun. 2008, Vol. 3, $\mathrm{N}^{\circ} 1$, Florianópolis.

Fontana, L. (2003): "Manifiesto Blanco", en Manifiestos argentinos. Política de lo visual, Cipollini, R. Adriana Hidalgo, Buenos Aires.

Frank, W. (1946): América hispânica. Casa do Estudante do Brasil, Rio de Janeiro. (Traducción de Anna A. de Queiroz Carneiro de Mendonça).

(1942): Ustedes y nosotros - Nuevo mensaje a Ibero-América. Losada, Buenos Aires.

Gold, M.: "Two Critics in a Bar-room", en Liberator, set. 1921, 28-31.

Goldwater, R. (1938): Primitivism and Modern Art. Belknap, Harvard.

Huidobro, V.: “La création pure”, en L'Esprit Nouveau, 1921, № 7, Paris.

Jesi, F. (2005): Bachofen. Bollati Boringhieri, Torino.

(1996): Lettura del "Bateau ivre" di Rimbaud. Quodlibet, Maccerata.

(1977): O Mito. Presença, Lisboa. (Traducción de Lemos de Azevedo).

Michaud, P. A. (2007): Aby Warburg and the Image in Motion, S. Hawkes (trans.), foreword by G. Didi-Huberman. Zone Books, New York. 
Moore, A.W.: "Holger Cahill y el inje-inje. La historia del primitivismo modernista", en Historias. Revista del Instituto Nacional de Antropología e Historia, may.-ago. de 2005, № 61, México.

Rhodes, C. (1994) Primitivism and Modern Art. Thames \& Hudson, Londres.

Rubin , W. (ed.) (1984): "Primitivism". 20 $0^{\text {th }}$ Century Art, 1984, Museo de Arte Moderno, Nueva York.

Saslavsky, L. 1929: "El cuentista Waldo Frank", en Síntesis, № 29, Buenos Aires.

Tablada, J. J. (1992): Diario (1900-1944), Guillermo Sheridan (ed.). Universidad Nacional Autónoma de México, México.

Zayas, M. (2005): Cómo, cuando y por qué el arte moderno llegó a Nueva York. Universidad Nacional Autónoma de México, México. (Estudio introductorio y traducción de Antonio Saborit).

Zimmermann, L. (ed.) (2006): Penser par les images. Autour des travaux de Georges Didi-Huberman. Editions Cécile Defaut, Nantes. 